\title{
PENGARUH VARIASI ARUS PENGELASAN SHIELD METAL ARC WELDING (SMAW) TERHADAP KEKUATAN TARIK PADA MATERIAL STAINLESS STEEL 304L
}

\author{
The Effect of The Variation of Welding Current of Shield Metal Arc Welding (SMAW) on The Tensile \\ Strength of Stainless Steel 304L \\ Moh. Ainul Yaqin ${ }^{1)}$, Nely Ana Mufarida ${ }^{2)}$, Kosjoko ${ }^{3)}$ \\ ${ }^{1,2,3)}$ Program Studi Teknik Mesin, Fakultas Teknik, Universitas Muhammadiyah Jember \\ Email : ${ }^{1)}$ ainulyaqin1997.inonk@gmail.com
}

\begin{abstract}
ABSTRAK
Proses pengelasan merupakan salah satu cara untuk menyambungkan dua bagian logam secara permanen dengan menggunakan energi panas yang diperoleh dari elektroda. Penelitian ini dilakukan dengan menggunakan metode eksperimen dengan memvariasikan kuat arus pengelasan pada spesimen baja Stainlesss Steel 304L. Selain itu, pada proses pengelasan menggunakan model butt weld joint dengan alur berbentuk V tunggal. Dari hasil penelitian dan analisis data, dapat diketahui bahwa nilai uji tarik yang diperoleh mengalami kenaikan seiring dengan meningkatnya variasi kuat arus pengelasan. Pada variasi kuat arus 73 A diperoleh nilai uji tarik rata-rata sebesar $704 \mathrm{~N} / \mathrm{mm}^{2}$. Untuk variasi kuat arus 78 A menghasilkan nilai rata-rata uji tarik sebesar $718 \mathrm{~N} / \mathrm{mm}^{2}$. Dan variasi kuat arus 80 A menghasilkan nilai uji tarik tertinggi yaitu sebesar $804 \mathrm{~N} / \mathrm{mm}^{2}$.
\end{abstract}

Kata Kunci : arus pengelasan, uji tarik, stainless steel 304L.

\begin{abstract}
The welding process is one way to permanently connect two metal parts by using heat energy obtained from the electrodes. This research was conducted using an experimental method by varying of the welding current on the Stainlesss Steel 304L specimens. In addition, the welding process used the butt weld joint model with a single Vshaped groove. From the results of research and data analysis, it can be seen that the value of the tensile test obtained increases with increasing variations in the welding current. In the current variation of $73 \mathrm{~A}$, the average tensile test value is $704 \mathrm{~N} / \mathrm{mm}^{2}$. For the variation of the strong current $78 \mathrm{~A}$ produced an average tensile test value of $718 \mathrm{~N} / \mathrm{mm}^{2}$. And the strong current variation of 80 A produces the highest tensile test value that is equal to $804 \mathrm{~N} / \mathrm{mm}^{2}$.
\end{abstract}

Keywords: welding current, tensile test, stainless steel 304L.

\section{PENDAHULUAN}

Perkembangan teknologi pada bidang konstruksi yang semakin maju tidak dapat dipisahkan dari pengelasan karena mempunyai peranan penting dalam rekayasa dan reparasi logam. Pembangunan konstruksi dengan logam pada masa sekarang ini banyak melibatkan unsur pengelasan, khususnya bidang rancang bangun. Pembuatan sambungan yang secara teknis memerlukan keterampilan yang tinggi agar diperoleh sambungan dengan kualitas baik. Lingkup penggunaan teknik pengelasan dalam konstruksi sangat luas meliputi perkapalan, jembatan, rangka baja, bejana tekan, sarana transportasi, rel, pipa saluran dan lain sebagainya.

Mesin las Shielded Metal Arc Welding (SMAW) berdasarkan arusnya dibedakan menjadi tiga macam yaitu mesin las arus searah atau Direct Current (DC), mesin las arus bolak-balik atau Alternating Current (AC) dan mesin las arus ganda yang merupakan mesin las yang dapat digunakan untuk pengelasan dengan arus searah (DC) dan pengelasan dengan arus bolakbalik (AC)[1].

Besarnya kuat arus pengelasan dapat berpengaruh terhadap hasil pengelasan [2]. Bila arus yang digunakan terlalu rendah akan menyebabkan sukarnya penyalaan busur listrik. Sehingga panas yang dihasilkan tidak cukup untuk melelehkan elektroda dan bahan kerja. Hasil pengelasannya merupakan rigirigi las yang kecil dan tidak rata serta penembusan kurang dalam. Sebaliknya bila arus terlalu tinggi maka elektroda akan mencair terlalu cepat dan menghasilkan permukaan las yang lebih lebar serta 
menembus terlalu dalam, sehingga menghasilkan kekuatan tarik yang rendah dan menambah kerapuhan dari hasil pengelasan [3].

Penelitian ini menggunakan bahan baja SS 304L yang diberi perlakuan pengelasan dengan variari kuat arus sebesar 73 Ampere, 78 Ampere dan 80 Ampere. Dengan menggunakan las SMAW DC polaritas terbalik dan elektroda E309L-16 berdiameter 2,6 mm serta jenis kampuh $\mathrm{V}$ dengan sudut $30^{\circ}$. Penelitian ini dilakukan untuk untuk mengetahui pengaruh variasi kuat arus pengelasan terhadap kekuatan tarik hasil sambungan las SMAW pada plat SS 304L.

\section{METODE PENELITIAN}

Penelitian ini menggunakan metode eksperimen dengan memvariasikan kuat arus pengelasan pada baja karbon rendah Stainless Steel (SS) 304L. Spesimen yang digunakan memiliki ukuran panjang $200 \mathrm{~mm}$, lebar $2.8 \mathrm{~mm}$, dan tebal $8 \mathrm{~mm}$, yang mengacu pada ASTM E8/E8M-09 tentang Standard Test Methods for Tension Testing of Metallic Materials[4].

Spesifikasi benda uji yang digunakan dalam eksperimen ini adalah sebagai berikut:

1) Bahan yang digunakan adalah plat baja SS 304L

2) Ketebalan plat $8 \mathrm{~mm}$, panjang $200 \mathrm{~mm}$, lebar 2.8 $\mathrm{mm}$.

3) Elektroda yang digunakan adalah jenis E309L-16 dengan diameter 2,6 mm.

4) Posisi pengelasan dengan menggunaklan posisi bawah tangan.

5) Arus pengelasan yang digunakan adalah $73 \mathrm{~A}$, 78A, 80A.

6) Kampuh yang digunakan jenis kampuh $\mathrm{V}$ terbuka, jarak celah plat $2 \mathrm{~mm}$, sudut kampuh $30^{\circ}$.

7) Bentuk spesimen benda uji mengacu standar JIS Z 22011981 untuk pengujian tarik.

Uji tarik dilakukan untuk mengetahui besar kekuatan tarik regangan dari spesimen tersebut. Berikut ini merupakan tahapan untuk melakukan uji tarik pada spesimen:

1) Mengukur dimensi spesimen (panjang, lebar, dan tinggi untuk spesimen bentuk plat)

2) Menentukan beban tertinggi yang dapat diberikan sebagai tahanan atau reaksi dari bahan terhadap beban luar

3) Menginput data hasil pengukuran spesimen kedalam program komputer dan melakukan pengaturan sesuai dengan sepesifikasi spesimen
4) Memasang spesimen pada alat uji dan selanjutnya dilakukan proses pengambilan data

5) Setelah data diperoleh, selanjutnya data disimpan dan mengulangi langkah-langkah pengujian diatas pada variasi spesimen yang lainnya

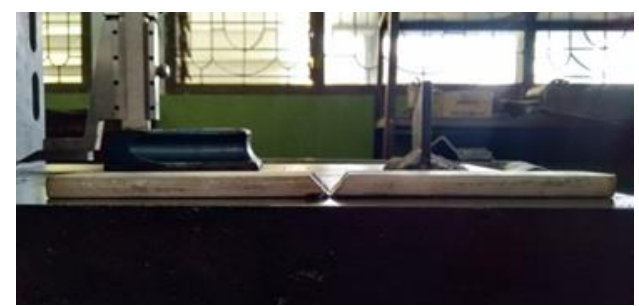

Gambar 1. Sambungan Kampuh V

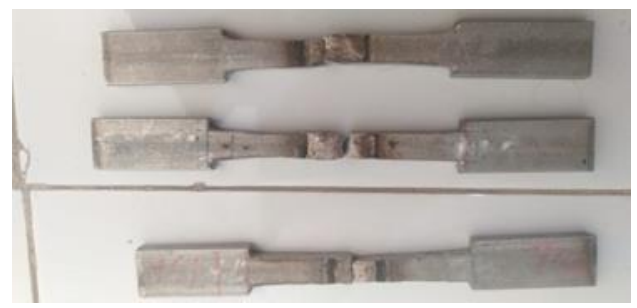

Gambar 2. Spesimen Pengujian

Setelah proses pengelasan selesai maka dilanjutkan pembuatan spesimen sesuai JIS Z 2201 1981, yang nantinya akan diuji tarik, langkah-langkahnya sebagai berikut:

1) Meratakan alur hasil pengelasan dengan mesin frais.

2) Memotong bahan dengan ukuran panjang 200 $\mathrm{mm}$ dan lebar $13 \mathrm{~mm}$.

3) Membuat gambar/mal yang mengacu pada ukuran standar JIS Z 22011981.

4) Membentuk spesimen sesuai gambar/mal dengan menggunakan mesin frais.

\section{HASIL DAN PEMBAHASAN}

Dari serangkaian pengujian yang telah dilakukan diperoleh hasil sebagai berikut:

Tabel 1 Hasil Uji Tarik

\begin{tabular}{|c|c|c|}
\hline Variasi & $\operatorname{Max} \operatorname{Stress}\left(\mathrm{N} / \mathrm{mm}^{2}\right)$ & Rata-rata \\
\hline \multirow{3}{*}{$73 \mathrm{~A}$} & 700 & \multirow{3}{*}{$704 \mathrm{~N} / \mathrm{mm}^{2}$} \\
\hline & 707 & \\
\hline & 705 & \\
\hline \multirow{3}{*}{$78 \mathrm{~A}$} & 715 & \multirow{3}{*}{$718 \mathrm{~N} / \mathrm{mm}^{2}$} \\
\hline & 721 & \\
\hline & 720 & \\
\hline \multirow{3}{*}{$80 \mathrm{~A}$} & 805 & \multirow{3}{*}{$804 \mathrm{~N} / \mathrm{mm}^{2}$} \\
\hline & 806 & \\
\hline & 802 & \\
\hline
\end{tabular}


Dari Tabel 1 dapat diketahui nilai uji tarik untuk semua variasi kuat arus pengelasan. Pada tabel tersebut dapat dilihat bahwa meningkatnya arus pengelasan berbanding lurus terhadap kenaikan nilai hasil uji tarik.

\section{KESIMPULAN}

Dari serangkaian uji coba penelitian ini dapat di simpulkan bahwa semakin besar kuat arus pengelasan yang di gunakan, maka hasil kekuatan uji tarik akan semakin besar, dan jika semakin kecil arus yang di gunakan maka kekuatan tarik akan semakin kecil.

\section{SARAN}

Untuk lebih menyempurnakan penelitian perlu adanya penelitian lebih lanjut dengan meneliti sifat fisik maupun mekaniknya, serta pengaruh micro struktur. Untuk mendapatkan kekuatan las yang baik pada pengelasan SMAW sebaiknya menggunakan pendingin udara bebas

\section{DAFTAR PUSTAKA}

[1] Alip, M. (1989). Teori dan Praktik Las. Proyek Pengembangan Lembaga Pendidikan Tenaga Kependidikan. Jakarta.

[2] Hanafi, A. (2012). Pengaruh Jenis Media Pendingin terhadap Kekuatan Tarik Sambungan Logam Las Plat Baja St-60 dengan Pengelasan MIG/MAG.

[3] Wiryosumarto, H. dan Okumura, T. (2000). Teknologi Pengelsan Logam. Pradnya Paramita. Jakarta.

[4] ASTM. (1990). Standard and Literature References For Composite Materials 2nd Edition. Philadelphia, USA 